\title{
Effects of dexmedetomidine versus remifentanil on mothers and neonates during cesarean section under general anesthesia
}

\author{
Zhiqiang Yua, ${ }^{a, b, \#}$, Peijun Zhang ${ }^{b, \#}$, Haiyun Wang ${ }^{a}$, Li Zhang ${ }^{b}$,Wei Wei ${ }^{b}$, Wenqian Fang ${ }^{b}$, Xingbo Muc
}

\begin{abstract}
Background and Aims. Dexmedetomidine and remifentanil use in obstetric general anesthesia is controversial. This study aimed to compare the effects of remifentanil and dexmedetomidine on mothers and neonates during cesarean section under general anesthesia.

Methods. A total of 120 patients scheduled for elective cesarean section under general anesthesia were randomly allocated to dexmedetomidine (D), remifentanil (R), and control (C) groups. Anesthesia was induced with propofol and muscle relaxants in all groups. Anesthesia in groups $D$ and $R$ was induced with dexmedetomidine (induction, $0.5 \mu \mathrm{g} /$ $\mathrm{kg}$; maintenance, $0.5 \mu \mathrm{g} / \mathrm{kg} \cdot \mathrm{h}$ ) and remifentanil (induction, $0.5 \mu \mathrm{g} / \mathrm{kg}$; maintenance, $2 \mu \mathrm{g} / \mathrm{kg} \cdot \mathrm{h}$ ), respectively, until birth. Group C received equivalent volumes of normal saline. Mean arterial blood pressure (MAP), heart rate (HR), plasma catecholamine, visual analog pain score (VAS), and total tramadol consumption at 1, 2, and 3 hours after extubation were recorded. Neonatal effects were assessed by Apgar scores and umbilical blood gas analysis.

Results. Post induction, MAP was significantly higher in group D compared to groups $C$ and $R$, and significantly lower in group $R$ than in group C. At intubation/skin incision and delivery, MAP, HR, and plasma epinephrine and norepinephrine concentrations were significantly lower in groups $D$ and $R$ than in group C. Compared to group R, MAP was significantly higher, and HR, plasma epinephrine, and norepinephrine concentrations were significantly lower in group $\mathrm{D}$. Compared with groups $C$ and $D$, the percentage of neonates with Apgar score $<7$ was higher in group $R$ at 1 min after delivery. Compared with groups $C$ and R, the VAS was significantly lower in group D at 1 and $2 \mathrm{~h}$ postoperatively. Total tramadol consumption was significantly lower in group $D$ at 3 hours postoperatively.
\end{abstract}

Conclusion. During general anesthesia for cesarean section, remifentanil demonstrated better control of hemodynamic stability, while dexmedetomidine demonstrated better neonatal Apgar scores, postoperative analgesia, and decreased catecholamine release.

Trial Registration: Chinese Clinical Trial Register (ChiCTR) - ChiCTR1800017125

Key words: general anesthesia, cesarean section, remifentanil, dexmedetomidine

Received: August 21, 2019; Revised: October 3, 2019; Accepted: November 4, 2019; Available online: November 19, 2019

https://doi.org/10.5507/bp.2019.055

(c) 2020 The Authors; https://creativecommons.org/licenses/by/4.0/

${ }^{a}$ Department of Anesthesiology, The Third Central Clinical College of Tianjin Medical University, Tianjin Third Central Hospital, Nankai University Affinity the Third Central Hospital, Tianjin Institute of Hepatobiliary Disease, Tianjin Key Laboratory of Extracorporeal Life Support for Critical Diseases, Tianjin 300170, China

${ }^{b}$ Department of Anesthesiology, Central Hospital of gynecology and obstetrics, Tianjin 300100, China

'Neonatal Department,Tianjin Central Hospital of gynecology and obstetrics, Tianjin 300100, China

"These authors contributed equally to this work

Corresponding author: Haiyun Wang, e-mail:why819@126.com

\section{INTRODUCTION}

Spinal anesthesia is generally the technique of choice in cesarean section; however, general anesthesia is the only option in cases with contraindications for spinal anesthesia. An ideal agent for obstetric general anesthesia should provide a smooth and rapid effect, minimize maternal stress response to tracheal intubation and nociceptive stimuli, and minimize respiratory depression of the neonate ${ }^{1}$. Propofol combined with muscle relaxants is routinely used for rapid sequential induction of general anesthesia in obstetric patients. However, there are risks of intraoperative awareness and hemodynamic instability due to the stress response caused by endotracheal intubation and surgical stimuli; the stress response could stimulate the sympathetic nervous system to release catecholamine and cause subsequent increases in blood pressure, HR, and left ventricular afterload, which may lead to maternal and neonatal complications. There has been a concern that the stress during tracheal intubation may potentially increase fetal risks by raising circulating catecholamine levels and thereby decreasing placental blood flow, which can adversely affect the neonate $^{2}$. Dexmedetomidine has sedative, anxiolytic, sympatholytic, and analgesic-sparing effects and causes minimal depression of respiratory function. Remifentanil is a short-acting opioid with a very short half-life and is rapidly metabolized by a non-specific plasma esterase, regardless of the duration of the infusion. Both dexmedetomidine and remifentanil have been shown to attenu- 
ate stress responses, creating a more stable hemodynamic profile during obstetric surgery ${ }^{3,4}$. However, both agents cross the uteroplacental barrier, so their use in obstetric general anesthesia is considered controversial because of the possible effects on the fetus. Dexmedetomidine and remifentanil use for obstetric general anesthesia have been compared only in a few studies, with varying conclusions. Therefore, in this study, we aimed to observe the effects of dexmedetomidine versus remifentanil on maternal MAP, $\mathrm{HR}$, catecholamine concentrations, postoperative analgesia, and neonates' Apgar scores during cesarean section under general anesthesia.

\section{MATERIALS AND METHODS}

\section{Participants}

This prospective double-blind, randomized controlled trial was approved by the Department of Anesthesiology, Department of Obstetrics, and the Medical Ethics Committee of the Tianjin Central Hospital of Gynecology and Obstetrics in China. Informed consent was obtained from each participant. Exclusion criteria were patient refusal, bradycardia, systemic diseases (e.g., cardiac, pulmonary, renal, hepatic, or neurological disorders, and diabetes mellitus), pregnancy-induced hypertension syndrome, fetal distress, and multiple pregnancies. From July 2018 to June 2019 (Fig. 1), we included 120 ASA I and II full-term pregnant women (gestational age 37-41 weeks) with spinal anesthesia contraindications (such as coagulation abnormalities, thrombocytopenia, aplastic anemia, vertebral deformity, and local infection), or failed spinal anesthesia and patients who were scheduled to receive general anesthesia for cesarean section, and their neonates (Fig. 1). Before surgery, the visual analog pain score (VAS) was explained to all patients (score 0 to 10 $\mathrm{cm}$, with 0 indicating no pain, and 10 indicating worst pain imaginable).

\section{Anesthesia}

When the patient arrived in the pre-operative holding area, an $18-\mathrm{G}$ intravenous cannula was placed in the right dominant forearm for administration of drugs and fluids, and an infusion of lactated Ringer's solution was commenced. Each patient was transferred to the operating table in the left lateral position, and a wedge was placed under the right hip to achieve a $15^{\circ}$ leftward uterine displacement. Pulse oximetry, continuous electrocardiography (ECG), and bispectral index (BIS) (BIS BeneVision N15Monitoring system, Mindray, China) were monitored; invasive blood pressure monitoring was also performed. Patients were divided randomly into three groups of 40 each as follows: dexmedetomidine group (D), remifentanil group ( $\mathrm{R}$ ) and control group (C), with codes contained in sealed, opaque envelopes.

The surgical site was scrubbed and draped using aseptic techniques; denitrogenification was performed with $100 \%$ oxygen for $3 \mathrm{~min}$ before administration. The envelopes were opened by an anesthesiologist to allocate the patients to different groups. In the three groups, anesthesia was induced with intravenous propofol $2 \mathrm{mg} / \mathrm{kg}$ given over $30 \mathrm{~s}$, and cisatracurium $0.2 \mathrm{mg} / \mathrm{kg}$ was administered over $5 \mathrm{~s}$. Except for the designer who did not perform anesthesia, neither the anesthesia provider nor the assessors knew the contents of the infusion. In group D, dexmedetomidine $0.5 \mu \mathrm{g} / \mathrm{kg}$ was used to induce over $90 \mathrm{~s}$, with maintenance at $0.5 \mu \mathrm{g} / \mathrm{kg} / \mathrm{h}$ until birth; In group R, remifentanil $0.5 \mu \mathrm{g} / \mathrm{kg}$ was used to induce over $90 \mathrm{~s}$, with maintenance at $2 \mu \mathrm{g} / \mathrm{kg} / \mathrm{h}$ until birth; the control group received equivalent volumes of normal saline to follow a double blind method. Tracheal intubation was performed by video laryngoscopy 3 min after induction, and the skin

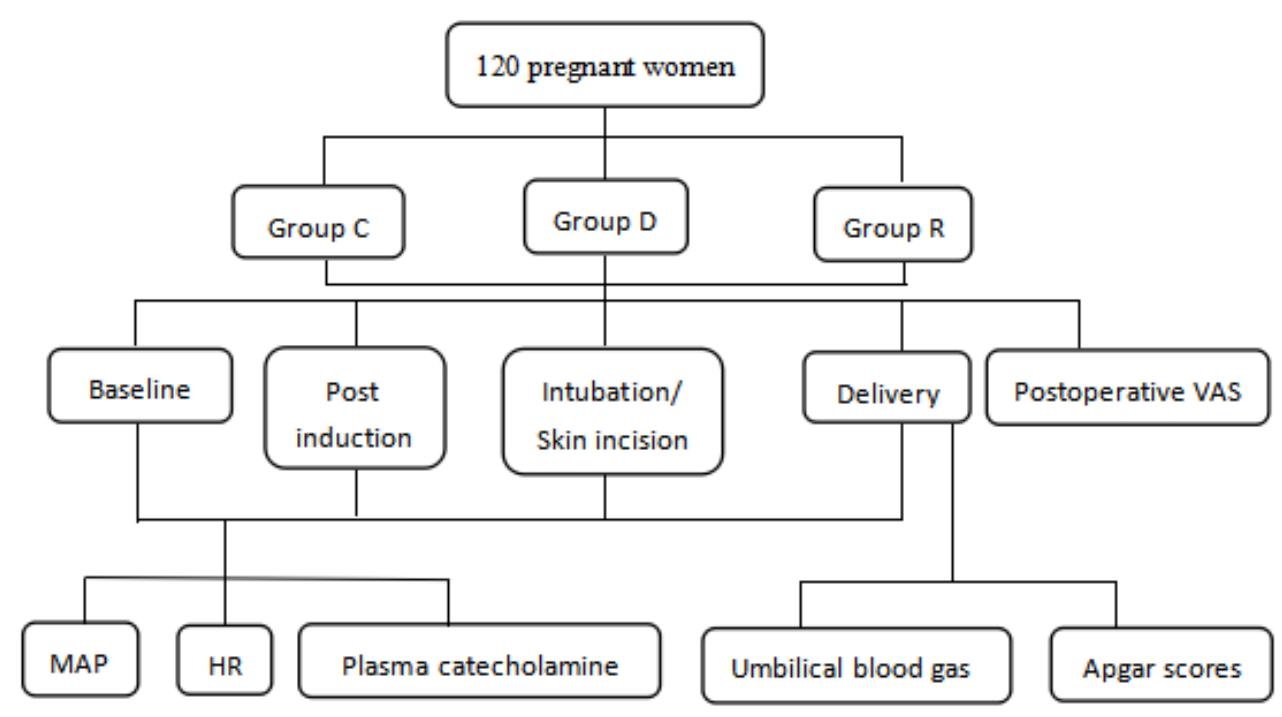

Fig. 1. Flow diagram of patient enrollment and data recording.

Group C: control group; Group D: dexmedetomidine group; Group R: remifentanil group. VAS: visual analog pain score. MAP: mean arterial blood pressure; HR, heart rate. 
Table 1. Maternal and surgical characteristics.

\begin{tabular}{|c|c|c|c|c|}
\hline & $\begin{array}{l}\text { Group C } \\
(n=40)\end{array}$ & $\begin{array}{l}\text { Group R } \\
(\mathrm{n}=40)\end{array}$ & $\begin{array}{l}\text { Group D } \\
(n=40)\end{array}$ & $P$ \\
\hline Maternal age (years) & $29.0 \pm 5.2$ & $30.0 \pm 4.1$ & $29.0 \pm 3.5$ & 0.492 \\
\hline Gestational age (weeks) & $39.8 \pm 2.4$ & $39.3 \pm 1.3$ & $38.6 \pm 3.5$ & 0.114 \\
\hline BMI $\left(\mathrm{kg} / \mathrm{m}^{2}\right)$ & $28.15 \pm 1.92$ & $28.24 \pm 1.70$ & $27.70 \pm 2.86$ & 0.508 \\
\hline Induction-to-cord clamping interval ( $\mathrm{min}$ ) & $7.85 \pm 1.75$ & $7.71 \pm 1.81$ & $7.89 \pm 2.90$ & 0.930 \\
\hline Duration of surgery $(\mathrm{min})$ & $37.18 \pm 6.51$ & $38.14 \pm 7.11$ & $36.24 \pm 7.07$ & 0.355 \\
\hline Sulfentanyl during surgery $(\mu \mathrm{g})$ & $25.2 \pm 5.8$ & $26.1 \pm 6.2$ & $24.8 \pm 7.1$ & 0.649 \\
\hline Recovery time (min) & $5.5 \pm 1.3$ & $5.8 \pm 2.9$ & $6.3 \pm 1.7$ & 0.225 \\
\hline
\end{tabular}

Values are presented as the mean \pm standard deviation. BMI: body mass index.

incision was performed at the same time. Oxygenation was ensured by assisting or controlling ventilation by hand during induction. Anesthesia was maintained by inhalation $1.7 \%$ sevoflurane, and the concentration of sevoflurane was adjusted to maintain maternal BIS values between 40-60. The lungs were mechanically ventilated with $60 \%$ oxygen, maintaining $\mathrm{ET}_{\mathrm{CO} 2}$ at $35-40 \mathrm{mmHg}$. After umbilical cord clamping, blood from the umbilical artery and vein was used for blood gas analysis. Neonatal Apgar scores were assessed at $1 \mathrm{~min}$ and $5 \mathrm{~min}$ by a pediatrician blinded to the study protocol. Gentle stimulation or active resuscitation was carried out as required to improve the Apgar scores; the requirement for resuscitation and admission into the neonatal intensive care unit (NICU) was also assessed by the pediatrician. After the neonate's umbilical cord was clamped, $0.05 \mathrm{mg} / \mathrm{kg}$ of midazolam was administered; $5 \mathrm{U}$ of oxytocin was added to $500 \mathrm{~mL} 0.9 \%$ saline and infused through a separate line, and pain was controlled by administering $0.3 \mu \mathrm{g} / \mathrm{kg}$ of sufentanil. After sufentanil administration, if the BIS values were lower than 40 or if MAP decreased markedly, the concentration of sevoflurane was reduced. MAP, HR, and plasma epinephrine and norepinephrine concentrations were measured at baseline, post induction, during intubation/skin incision, and at delivery. Plasma concentrations of norepinephrine and epinephrine were measured in the clinical laboratory. At the end of the surgery, sevoflurane was stopped, and when patients regained consciousness and began breathing by themselves, residual neuromuscular block was antagonized using neostigmine $0.03 \mathrm{mg} / \mathrm{kg}$ and atropine $0.015 \mathrm{mg} / \mathrm{kg}$ intravenously in all patients. Recovery time (from skin closure to extubation) and VAS at 1, 2, and 3 hours postoperatively were recorded. Postoperatively, a bolus of tramadol $1.5 \mathrm{mg} /$ $\mathrm{kg}$ was administered by intravenous injection when the VAS was at least 4. Ephedrine $7.5 \mathrm{mg}$ was administered in response to a $20 \%$ decrease from baseline MAP, and $0.5 \mathrm{mg}$ atropine was administered in response to bradycardia $(\mathrm{HR}<45 \mathrm{bpm})$.

\section{Statistical analysis}

Statistical analysis of data was performed using SPSS 20.0. Measurement data were expressed as mean \pm standard deviation $(\bar{x} \pm \mathrm{s})$. One-way analysis of variance (oneway ANOVA) was used to analyze the differences between the groups. The percentages of neonates with an Apgar score $<7$ were analyzed with Chi-square test. A $P$-value $<0.05$ was considered statistically significant.

\section{RESULTS}

A total of 120 pregnant women with a term pregnancy, aged 18-42 years, were enrolled in the study. None of the patients was able to recall the perioperative events postoperatively. During the time from administration of dexmedetomidine to delivery, atropine $0.5 \mathrm{mg}$ was injected for bradycardia in 2 cases from group $\mathrm{D}$, and ephedrine $7.5 \mathrm{mg}$ was administered for hypotension in 1 case from group R. MAP, HR, and plasma epinephrine and norepinephrine concentrations in the three cases were excluded from the analysis. Maternal age, gestational age, body mass index (BMI), duration of surgery, inductionto-cord clamping interval, total sufentanil consumption, and recovery time were not significantly different among the three groups (Table 1).

\section{Maternal MAP and HR}

At baseline, there were no differences in MAP and HR among the three groups. Post induction MAP was significantly higher, and the HR was significantly lower in group D than in groups C and R. MAP was significantly lower in group $\mathrm{R}$ than in group $\mathrm{C}$; HR was not significantly different between groups $\mathrm{R}$ and $\mathrm{C}$. At the time of intubation/skin incision and delivery, MAP and HR were significantly lower in groups $\mathrm{D}$ and $\mathrm{R}$ than in group $\mathrm{C}$; MAP was significantly higher, and the HR was significantly lower in group D than in group R (Fig. 2 A,B).

\section{Maternal plasma epinephrine and norepinephrine concentrations}

At baseline, plasma epinephrine and norepinephrine concentrations were not significantly different among the three groups. Post induction, plasma epinephrine and norepinephrine concentrations were significantly lower in group D than in groups $\mathrm{C}$ and $\mathrm{R}$; plasma epinephrine and norepinephrine concentrations were not significantly different between groups $\mathrm{R}$ and $\mathrm{C}$. At the time of intubation/skin incision and delivery, plasma epinephrine and norepinephrine concentrations were significantly lower in 


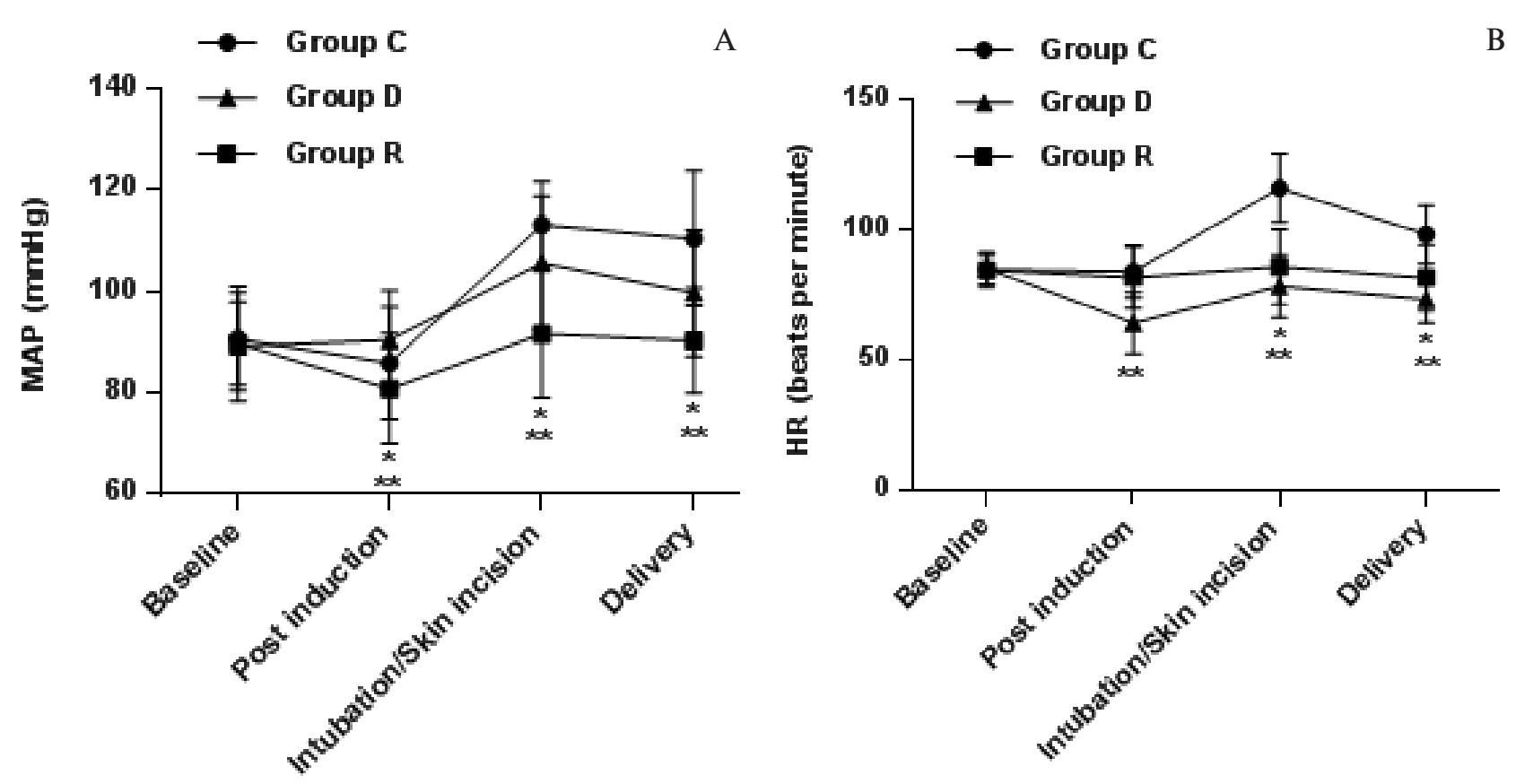

Fig. 2. The MAP and HR in the three groups.

Compared with the control group, MAP were significantly lower in dexmedetomidine group at post induction, intubation/skin incision and delivery, ${ }^{*} P<0.05$; compared with the control and dexmedetomidine group, MAP were significantly lower in remifentanil group at post induction, intubation/skin incision and delivery, ${ }^{*} P<0.05$ (A). Compared with the control group, HR were significantly lower in remifentanil group at intubation/ skin incision and delivery, ${ }^{*} P<0.05$; Compared with the control and remifentanil group, HR were significantly lower in dexmedetomidine group at post induction, intubation/skin incision and delivery, ${ }^{* *} P<0.05$ (B). Values are presented as the mean \pm standard deviation.
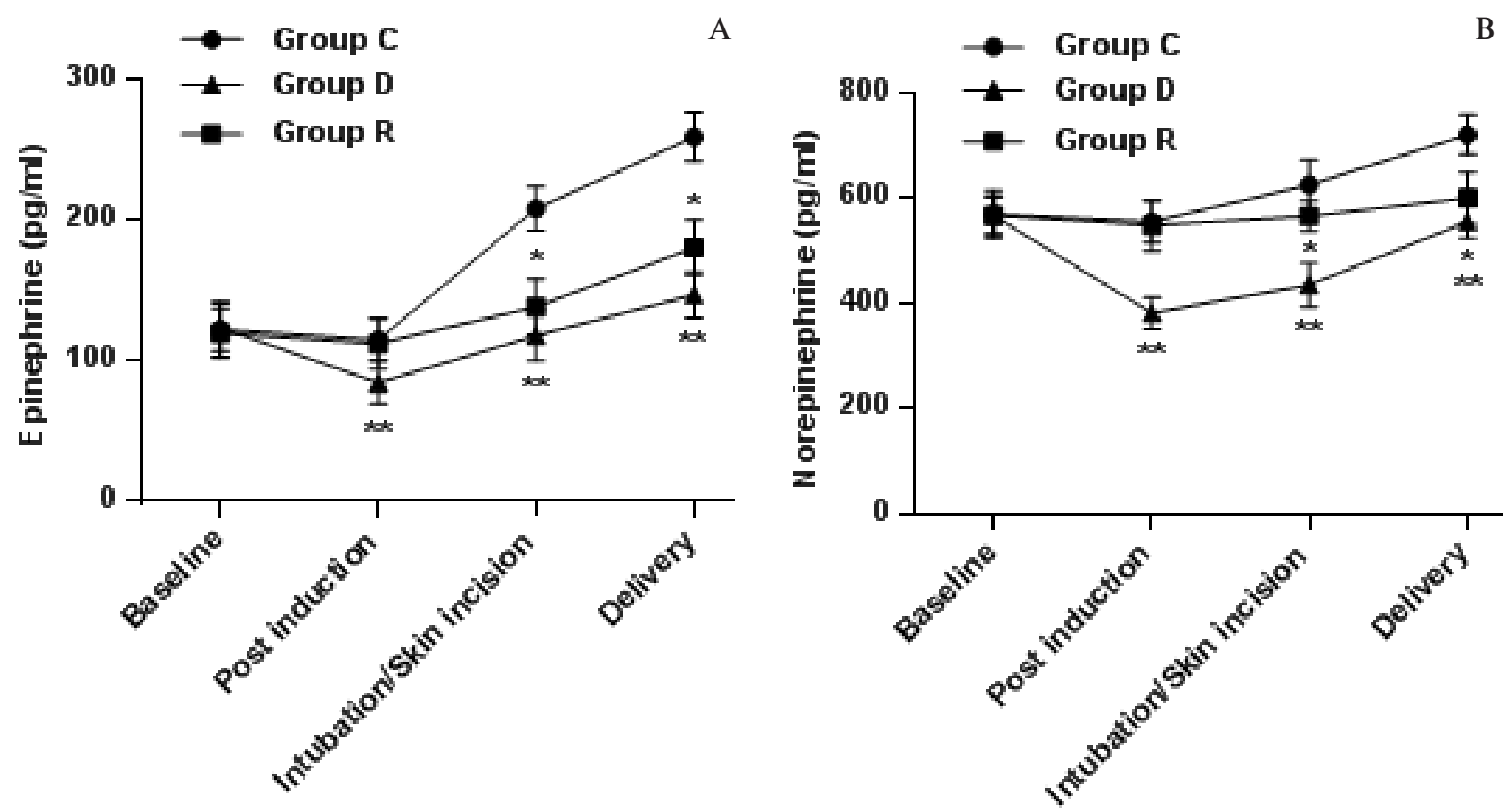

Fig. 3. The epinephrine and norepinephrine concentrations in the three groups.

Compared with the control group, the epinephrine and norepinephrine concentrations were significantly lower in remifentanil group at intubation/skin incision and delivery, ${ }^{*} P<0.05$. Compared with the control and remifentanil group, the epinephrine and norepinephrine concentrations were significantly lower in dexmedetomidine group at post induction, intubation/skin incision and delivery, ${ }^{* *} P<0.05$. Values are presented as the mean \pm standard deviation. 
Table 2. Maternal postoperative VAS and total tramadol consumption.

\begin{tabular}{lcccc}
\hline & $\begin{array}{c}\text { Group C } \\
(\mathrm{n}=40)\end{array}$ & $\begin{array}{c}\text { Group R } \\
(\mathrm{n}=40)\end{array}$ & $\begin{array}{c}\text { Group D } \\
(\mathrm{n}=40)\end{array}$ & $P$ \\
\hline Postoperative VAS & & & & \\
$1 \mathrm{~h}$ & $5.2 \pm 1.13$ & $4.9 \pm 1.07$ & $1.9 \pm 0.89^{*}$ & $<0.001$ \\
$\mathrm{~h}$ & $4.4 \pm 1.10$ & $4.3 \pm 1.05$ & $3.2 \pm 1.06^{*}$ & $<0.001$ \\
$3 \mathrm{~h}$ & $3.6 \pm 1.08$ & $3.4 \pm 1.12$ & $3.3 \pm 1.23$ & 0.493 \\
Total tramadol consumption (mg) & $152 \pm 18.0$ & $146 \pm 21.0$ & $80 \pm 22.0^{*}$ & $<0.001$ \\
\hline
\end{tabular}

* $P<0.05$ compared with the control and remifentanil groups.Values are presented as the mean \pm standard deviation.

Table 3. Umbilical blood gases values.

\begin{tabular}{|c|c|c|c|c|}
\hline & $\begin{array}{l}\text { Group C } \\
(\mathrm{n}=40)\end{array}$ & $\begin{array}{l}\text { Group R } \\
(\mathrm{n}=40)\end{array}$ & $\begin{array}{l}\text { Group D } \\
(\mathrm{n}=40)\end{array}$ & $P$ \\
\hline \multicolumn{5}{|l|}{ Umbilical venous } \\
\hline $\mathrm{pH}$ & $7.37 \pm 0.089$ & $7.35 \pm 0.078$ & $7.38 \pm 0.102$ & 0.390 \\
\hline PCO2 (mm Hg) & $39.3 \pm 4.0$ & $38.4 \pm 5.1$ & $38.6 \pm 4.7$ & 0.659 \\
\hline $\mathrm{PO} 2(\mathrm{~mm} \mathrm{Hg})$ & $50.3 \pm 6.5$ & $51.2 \pm 6.7$ & $50.1 \pm 7.5$ & 0.751 \\
\hline Base excess (mmol/L) & $-1.6 \pm 0.9$ & $-1.3 \pm 0.5$ & $-1.5 \pm 0.4$ & 0.105 \\
\hline \multicolumn{5}{|l|}{ Umbilical arterial } \\
\hline $\mathrm{pH}$ & $7.31 \pm 0.032$ & $7.32 \pm 0.044$ & $7.29 \pm 0.056$ & 0.071 \\
\hline $\mathrm{PCO} 2(\mathrm{~mm} \mathrm{Hg}) 49.1 \pm 5.7$ & $49.1 \pm 5.7$ & $48.8 \pm 6.5$ & $47.9 \pm 6.0$ & 0.656 \\
\hline $\mathrm{PO} 2(\mathrm{~mm} \mathrm{Hg})$ & $32.7 \pm 5.9$ & $31.5 \pm 6.1$ & $30.9 \pm 5.5$ & 0.376 \\
\hline Base excess $(\mathrm{mmol} / \mathrm{L})$ & $-2.1 \pm 0.82$ & $-1.8 \pm 0.70$ & $-2.0 \pm 0.42$ & 0.128 \\
\hline
\end{tabular}

Values are presented as the mean \pm standard deviation.

Table 4. The percentage of neonates with an Apgar score $<7$.

\begin{tabular}{lcccc}
\hline & $\begin{array}{c}\text { Group C } \\
(\mathrm{n}=40)\end{array}$ & $\begin{array}{c}\text { Group R } \\
(\mathrm{n}=40)\end{array}$ & $\begin{array}{c}\text { Group D } \\
(\mathrm{n}=40)\end{array}$ & $P$ \\
\hline $1 \mathrm{~min}$ & $8(20.0 \%)$ & $17(42.5 \%)^{*}$ & $7(17.5 \%)$ & 0.020 \\
$5 \mathrm{~min}$ & $1(2.5 \%)$ & $3(7.5 \%)$ & $2(5 \%)$ & 0.591 \\
$10 \mathrm{~min}$ & 0 & $1(2.5 \%)$ & $1(2.5 \%)$ & - \\
\hline
\end{tabular}

${ }^{*} P<0.05$ compared with the control and dexmedetomidine groups.

groups D and $\mathrm{R}$ than in group $\mathrm{C}$; plasma epinephrine and norepinephrine concentrations were significantly lower in group D than in groups R (Fig. 3 A,B).

\section{The effects on maternal postoperative analgesia}

Compared with groups $\mathrm{C}$ and $\mathrm{R}$, the VAS was significantly lower in group $\mathrm{D}$ at 1 and 2 hours postoperatively; there were no differences at 3 hours postoperatively among the three groups. At 3 hours postoperatively, the total tramadol consumption was significantly lower in group D than in groups $\mathrm{C}$ and $\mathrm{R}$; however, there were no differences between group $\mathrm{C}$ and group $\mathrm{R}$ (Table 2).

\section{The percentage of neonates with an Apgar score $<7$}

Umbilical venous and arterial blood gas values were similar in the three groups (Table 3). Compared with group $\mathrm{C}$ and $\mathrm{D}$, the percentage of neonates with an Apgar score $<7$ was higher in group $\mathrm{R}$ at $1 \mathrm{~min}$ after delivery; however, there was no difference between groups $\mathrm{C}$ and D. There were no differences in the percentage of neonates with an Apgar score $<7$ at 5 min after delivery among the three groups (Table 4).

In 32 of the 120 neonates born with an Apgar score $<7$ at 1 min after delivery, gentle stimulation could raise the Apgar score to $>7$ in most neonates, while ten neonates required bag-mask ventilation. Two neonates required endotracheal tube insertion and ventilation due to desaturation associated with respiratory distress syndrome and wet lung syndrome; among them, 1 case was from group D and 1 case was from group R. At 5 min after delivery, all neonates with a low Apgar score $(<7)$ were admitted for close observation for at least 24 hours in NICU. There were no neonatal deaths.

\section{DISCUSSION}

In this study, we observed the effects of dexmedetomidine and remifentanil combined with propofol on maternal MAP, HR, plasma catecholamine concentrations, 
postoperative analgesia, and neonates' Apgar scores. There are two studies that have compared the differences between dexmedetomidine and remifentanil in obstetric general anesthesia; they found that both remifentanil and dexmedetomidine are effective in controlling hemodynamic responses to sympathetic stimuli, and that remifentanil is better than dexmedetomidine in controlling hemodynamic stability. Doses of 0.4 or $1 \mu \mathrm{g} / \mathrm{kg}$ dexmedetomidine and $1 \mu \mathrm{g} / \mathrm{kg}$ remifentanil were safe to use in neonates during induction, but $2 \mu \mathrm{g} / \mathrm{kg}$ remifentanil has the potential to cause neonatal transient respiratory depression. Compared with a previous study ${ }^{5,6}$, the dosage of remifentanil was smaller in this study, and we administered a bolus of remifentanil and dexmedetomidine, but at a loading dose over $10 \mathrm{~min}$ during induction to decrease the fetal exposure time to general anesthetics. We found that a bolus of $0.5 \mu \mathrm{g} / \mathrm{kg}$ remifentanil had the potential to reduce the Apgar score at $1 \mathrm{~min}$. Furthermore, we evaluated the maternal catecholamine levels and postoperative analgesia.

\section{The effects of dexmedetomidine and remifentanil on maternal hemodynamic and catecholamine}

Hemodynamic effects of dexmedetomidine include hypertension and hypotension, owing to pre- and postsynaptic $\mathrm{a}_{2}$-receptor activation, which causes vasoconstriction, vasodilatation, and reflex bradycardia ${ }^{7}$. MAP was significantly higher, and HR was significantly lower in group $\mathrm{D}$ than in the other two groups after induction (Fig. 2 A,B); there were two cases with $\mathrm{HR}<45$, and we did not observe significant hypotension in group D. In this study, we found that dexmedetomidine was more effective than remifentanil in controlling catecholamine concentrations (Fig. 3 A,B). The possible reasons for this are as follows: remifentanil reduces the release of catecholamine by attenuating the stress responses, while dexmedetomidine not only reduces the stress response but also decreases the plasma catecholamine concentration directly. This finding is consistent with previously published results ${ }^{8}$. Dexmedetomidine was found to be effective in suppressing the noradrenaline level in a patient with pheochromocytoma ${ }^{9}$. However, the mechanism of action involved in this effect is not yet clear.

In non-obstetric surgery, opioids have been successfully used to attenuate the hemodynamic and catecholamine responses following tracheal intubation. A systematic review and meta-analysis of randomized controlled trials indicated remifentanil and alfentanil appear to be safer than fentanyl, with no significant effect on Apgar scores or neonatal airway intervention ${ }^{10}$. Remifentanil crosses the placenta rapidly in significant amounts and is rapidly metabolized by a non-specific plasma esterase, regardless of the duration of infusion. The use of remifentanil for induction and maintenance in obstetric general anesthesia has some advantages. It reduces the cardiovascular response to laryngoscopy and tracheal intubation, provides hemodynamic stability during airway manipulation and surgery, reduces the risk of maternal awareness, and provides adequate analgesia. Most studies ${ }^{11-13}$ demonstrated that a single bolus of either 0.5 or $1 \mu \mathrm{g} / \mathrm{kg}$ remifentanil effectively attenuated hemodynamic and catecholamine responses to laryngoscopy and tracheal intubation in healthy pregnant women or in those with severe pre-eclampsia undergoing cesarean delivery. However, in another study ${ }^{14}$, no significant differences were observed in hemodynamics or catecholamine concentrations on administration of 0.5 $\mu \mathrm{g} / \mathrm{kg}$ remifentanil bolus before induction, followed by a continuous infusion at $0.15 \mu \mathrm{g} / \mathrm{kg}$ min until peritoneal incision. We found that $0.5 \mu \mathrm{g} / \mathrm{kg}$ remifentanil controlled the hemodynamic responses to stress stimuli better than dexmedetomidine (Fig. 2A,B), and the present study indicated that remifentanil decreased stress response and plasma catecholamine concentrations in a stressed state (Fig. 3A,B).

\section{The effects of dexmedetomidine on maternal postoperative analgesia}

There were no differences in the sufentanil dose between the three groups (Table 1), so the post-op analgesia effects of sufentanil administration were minimal in the studied groups. Elimination half-life of dexmedetomidine is $2.1-3.1 \mathrm{~h}$ in healthy volunteers ${ }^{15}$. In ICU patients, similar values were found, with half-lives ranging from 2.2 to $3.7 \mathrm{~h}$ (ref. ${ }^{16,17}$ ). In this study, dexmedetomidine enhanced analgesia, decreased VAS, and reduced tramadol consumption at $3 \mathrm{~h}$ postoperatively.

\section{The effects of remifentanil and dexmedetomidine on neonates}

In healthy pregnant women ${ }^{18}$ and in those with severe pre-eclampsia ${ }^{19,20}$, all doses of remifentanil were associated with a possible transient respiratory depression in newborns ${ }^{21}$, and higher doses $(>1 \mu \mathrm{g} / \mathrm{kg})$ were associated with a potential $13 \%$ maternal hypotension ${ }^{22,23}$. Therefore, in obstetric general anesthesia, remifentanil should be used with adequate facilities for neonatal resuscitation. Similar to other anesthetic drugs, dexmedetomidine can pass through the placental barrier, but the placental transfer of dexmedetomidine (fetal:maternal ratio, 76\%) (ref. ${ }^{24}$ ) is considerably lower than that of remifentanil (fetal:maternal ratio, $88 \%$ ) $\left(\right.$ ref..$^{25}$ ); moreover, dexmedetomidine is more lipid soluble and is easily retained in the placental tissues, and the depression of respiratory function is minimal, so the percentage of neonates with Apgar score $<7$ was higher in group $\mathrm{R}$ than in group $\mathrm{D}$. However, remifentanil is rapidly metabolized in neonates; thus, at 5 min, there were no differences in the percentage of neonates with an Apgar score $<7$ among the three groups. This result is consistent with that reported in previous studies $^{1,11}$. In this study, there were no differences in Apgar scores between groups D and C. In concordance with our results, studies ${ }^{26,27}$ have shown that the mean Apgar scores were 8 and 9 at 1 and 5 min when dexmedetomidine was used in obstetric general anesthesia.

There are several limitations to our study. First, the catecholamine concentrations in the umbilical artery and vein were not measured; the effects of dexmedetomidine and remifentanil in the neonates were only assessed by evaluating Apgar scores and umbilical blood gas analysis. Second, as we did not have rocuronium and suxa- 
methonium in our institution, we chose cis-atracurium to perform general induction; therefore, this was not a standard rapid-sequence induction protocol. Third, maternal catecholamine concentration was not measured after extubation, and we only included a small number of patients. Therefore, more studies will be needed to evaluate the safety of remifentanil and dexmedetomidine in both mothers and their neonates during cesarean section under general anesthesia.

\section{CONCLUSION}

Our study demonstrated that remifentanil and dexmedetomidine attenuated the stress response to tracheal intubation and surgery during cesarean section under general anesthesia. Remifentanil showed better performance in terms of controlling hemodynamic fluctuations and responses to sympathetic stimuli; in contrast, dexmedetomidine was better in terms of the neonates' Apgar scores, postoperative analgesia, and reducing catecholamine release. Our findings suggest that dexmedetomidine and remifentanil can be useful adjuncts during rapid sequential induction of anesthesia in parturients in whom the hemodynamic status is unfavorable; however, their effects on both mothers and the neonates must be considered.

\section{ABBREVIATIONS}

MAP, mean arterial blood pressure; HR, heart rate; VAS,visual analog pain score;ECG,continuous electrocardiography; BIS, bispectral index; NICU,the neonatal intensive care unit.

Acknowledgment. This work was supported by the National Natural Science Foundation of China (81571054), Tianjin Major Support Program of Science and Technology (18YFZCSY00530), and Tianjin Central Hospital of Gynecology and Obstetrics in China. ChiCTR1800017125.

Author contributions: All authors have made substantive intellectual contributions to the manuscript; HW, ZY: designed the study; WF, PZ, LZ, MX: were responsible for conducting the study; ZY, WW: wrote the manuscript and analysed the data; HW: revised the manuscript. All authors have seen the original study data, reviewed the data analysis and approved the final manuscript.

Conflict of interests: The authors state that there are no conflicts of interest regarding the publication of this article.

\section{REFERENCES}

1. Gin T,O'Meara ME, Kan AF,Leung RK, Tan P, Yau G. Plasma catecholamines and neonatal condition after induction of anaesthesia with propofol or thiopentone at caesarean section. Br J Anaesth 1993;70:311-6.

2. Sulaiman S, Karthekeyan RB, Vakamudi M, Sundar AS, Ravullapalli $\mathrm{H}$, Gandham R. The effects of dexmedetomidine on attenuation of stress response to endotracheal intubation in patients undergoing elective off-pump coronary artery bypass grafting. Ann Card Anaesth 2012;15:39-43.

3. Kunisawa T, Ueno M, Kurosawa A, Nagashima M, Hayashi D, Sasakawa T, Suzuki A, Takahata O, Iwasaki H. Dexmedetomidine can stabilize hemodynamics and spare anesthetics before cardiopulmonary bypass. J Anesth 2011;25:818-22.

4. Winterhalter M, Brandl K, Rahe-Meyer N, Osthaus A, Hecker $\mathrm{H}$, Hagl C, Adams H A, Piepenbrock S. Endocrine stress response and inflammatory activation during CABG surgery. A randomized trial comparing remifentanil infusion to intermittent fentanyl. Eur J Anaesthesiol 2008;25:326-35.

5. Heesen M, Klöhr S, Hofmann T, Rossaint R, Devroe S, Straube S, Van de Velde M. Maternal and foetal effects of remifentanil for general anaesthesia in parturients undergoing caesarean section: a systematic review and meta-analysis. Acta Anaesthesiol Scand 2013 57:1-8.

6. Kart K, Hanci A. Effects of remifentanil and dexmedetomidine on the mother's awareness and neonatal Apgar scores in caesarean section under general anaesthesia. J Int Med Res 2018;46(5):1846-54.

7. Weerink MAS, Struys MMRF, Hannivoort LN, Barends CRM, Absalom AR, Colin P. Clinical Pharmacokinetics and Pharmacodynamics of Dexmedetomidine. Clin Pharmacokinet 2017;56:893-913.

8. Yoo KY, Jeong CW, Park BY, Kim SJ, Jeong ST, Shin MH, Lee J. Effects of remifentanil on cardiovascular and bispectral index responses to endotracheal intubation in severe pre-eclamptic patients undergoing Caesarean delivery under general anaesthesia. Br J Anaesth 2009;102(6):812-19.

9. Park BY, Jeong CW, Jang EA, Kim SJ, Jeong ST, Shin MH, Lee J, Yoo $\mathrm{KY}$. Dose-related attenuation of cardiovascular responses to tracheal intubation by intravenous remifentanil bolus in severe preeclamptic patients undergoing Caesarean delivery. $\mathrm{Br} J$ Anaesth 2011;106(1):82-7.

10. White LD, Hodsdon A, An GH, Thang C, Melhuish TM, Vlok R. Induction opioids for caesarean section under general anaesthesia: a systematic review and meta-analysis of randomised controlled trials. Int J Obstet Anesth 2019;40:4-13. doi: 10.1016/j.ijoa.2019.04.007

11. Draisci G, Valente A, Suppa E, Frassanito L, Pinto R, Meo F, De Sole $P$, Bossù $E$, Zanfini BA. Remifentanil for cesarean section under general anesthesia: effects on maternal stress hormone secretion and neonatal well-being: a randomized trial. Int J Obstet Anesth 2008;17:130-6.

12. Singh S, Singh A. Dexmedetomidine induced catecholamine suppression in pheochromocytoma. J Nat Sci Biol Med 2014;5:182.

13. Moura E, Afonso J, Hein L, Vieira-Coelho MA. Alpha2-adrenoceptor subtypes involved in the regulation of catecholamine release from the adrenal medulla of mice. Br J Pharmacol 2006;149:1049.

14. Ngan Kee WD1, Khaw KS, Ma KC, Wong AS, Lee BB, Ng FF. Maternal and neonatal effects of remifentanil at induction of general anesthesia for cesarean delivery: a randomized, double- blind, controlled trial. Anesthesiology 2006;104:14-20.

15. Yoo KY, Kang DH, Jeong H, Jeong CW, Choi YY, Lee J. A dose-response study of remifentanil for attenuation of the hypertensive response to laryngoscopy and tracheal intubation in severely preeclamptic women undergoing caesarean delivery under general anaesthesia. Int J Obstet Anesth 2013;22:10-18.

16. Eskandr AM, Metwally AA, Ahmed AA, Elfeky EM, Eldesoky IM, Obada MA, Abd-Elmegid OA. Dexmedetomidine as a part of general anaesthesia for caesarean delivery in patients with pre-eclampsia. Eur J Anaesthesiol 2018;35(5):1-7.

17. Welzing L, Ebenfeld S, Dlugay V, Wiesen MH, Roth B, Mueller C. Remifentanil degradation in umbilical cord blood of preterm infants. Anesthesiology 2011;114:570-7.

18. Ngan Kee WD, Khaw KS, Ma KC, Wong AS, Lee BB, Ng FF. Maternal and neonatal effects of remifentanil at induction of general anesthesia for cesarean delivery: a randomized, doubleblind, controlled trial. Anesthesiology 2006;104:14-20.

19. Booth CM, Buckley H, Wheatly S, Maguire S. Attenuation of the hypertensive response to tracheal intubation in patients with severe preeclampsia: a UK postal survey. Int J Obstet Anesth 2011;20:102-3.

20. Yu M, Han C, Jiang X, Wu X, Yu L, Ding Z. Effect and placental transfer of dexmedetomidine during caesarean section under general anaesthesia. Basic Clin Pharmacol Toxicol 2015;117:204-8.

21. Shen MK, Wu ZF, Zhu AB, He LL, Shen XF, Yang JJ, Feng SW. Remifentanil forlabour analgesia: a doubleblinded, randomized con- 
trolled trial of maternal and neonatal effects of patient-controlled analgesia versus continuous infusion. Anaesthesia 2013;68:236-44.

22. Abu-Halaweh SA, Al Oweidi AK, Abu-Malooh H, Zabalawi M, Alkazaleh F, Abu-Ali H, Ramsay MA. Intravenous dexmedetomidine infusion for labour analgesia in patient with preeclampsia. Eur J Anaesthesiol 2009;26:86-7.

23. Min Yu, Chuanbao Han, Xiuhong Jiang, Xia Wu, Li Yu, Zhengnian Ding. Effect and placental transfer of dexmedetomidine during caesarean section under general anaesthesia. Basic Clin Pharmaco Toxicol 2015;117:204-8.

24. Yoo H, lirola T, Vilo S, Manner T, Aantaa R, Lahtinen M, Scheinin M, Olkkola KT, Jusko WJ. Mechanism-based population pharmacokinetic and pharmacodynamic modeling of intravenous and intra- nasal dexmedetomidine in healthy subjects. Eur J Clin Pharmacol 2015;71:1197-207.

25. Lee S, Kim BH, Lim K, Stalker D, Wisemandle W, Shin SG, Jang IJ, Yu KS.Pharmacokinetics and pharmacodynamics of intravenous dexmedetomidine in healthy Korean subjects. J Clin Pharm Ther 2012;37:698-703.

26. lirola T, Aantaa R, Laitio R, Kentala E, Lahtinen M, Wighton A, Garratt C, Ahtola-Sätilä T, Olkkola KT. Pharmacokinetics of prolonged infusion of high-dose dexmedetomidine in critically ill patients. Crit Care 2011;15:R257.

27. Zhang T, Deng Y, He P, He Z, Wang X. Effects of mild hypoalbuminemia on the pharmacokinetics and pharmacodynamics of dexmedetomidine in patients after major abdominal or thoracic surgery. J Clin Anesth 2015;27:632-7.

\section{Supplemental Material:}

The online version of this article (doi: $10.5507 /$ bp.2019.055) offers supplemental material 